\title{
Cognitive impairment in elderly people
}

Citation for published version (APA):

Jolles, J., Verhey, F. R. J., Riedel, W. J., \& Houx, P. J. (1995). Cognitive impairment in elderly people: predisposing factors and implications for experimental drug studies. Drugs \& Aging, 7(6), 459-479. https://doi.org/10.2165/00002512-199507060-00006

Document status and date:

Published: 01/01/1995

DOI:

10.2165/00002512-199507060-00006

Document Version:

Publisher's PDF, also known as Version of record

Document license:

Taverne

Please check the document version of this publication:

- A submitted manuscript is the version of the article upon submission and before peer-review. There can be important differences between the submitted version and the official published version of record.

People interested in the research are advised to contact the author for the final version of the publication, or visit the DOI to the publisher's website.

- The final author version and the galley proof are versions of the publication after peer review.

- The final published version features the final layout of the paper including the volume, issue and page numbers.

Link to publication

\footnotetext{
General rights rights.

- You may freely distribute the URL identifying the publication in the public portal. please follow below link for the End User Agreement:

www.umlib.nl/taverne-license

Take down policy

If you believe that this document breaches copyright please contact us at:

repository@maastrichtuniversity.nl

providing details and we will investigate your claim.
}

Copyright and moral rights for the publications made accessible in the public portal are retained by the authors and/or other copyright owners and it is a condition of accessing publications that users recognise and abide by the legal requirements associated with these

- Users may download and print one copy of any publication from the public portal for the purpose of private study or research.

- You may not further distribute the material or use it for any profit-making activity or commercial gain

If the publication is distributed under the terms of Article $25 \mathrm{fa}$ of the Dutch Copyright Act, indicated by the "Taverne" license above, 


\title{
Cognitive Impairment in Elderly People \\ Predisposing Factors and Implications for Experimental Drug Studies
}

\author{
J. Jolles, F.R.J. Verhey, W.J. Riedel and P.J. Houx
}

Maastricht Brain and Behaviour Institute, and Department of Psychiatry and Neuropsychology, Limburg University, Maastricht, The Netherlands

\section{Contents}

Summary $\ldots \ldots \ldots \ldots \ldots \ldots \ldots \ldots \ldots \ldots$

1. Cognitive Aging in Healthy Individuals . . . . . . . . . . . . . . . . . . . 461

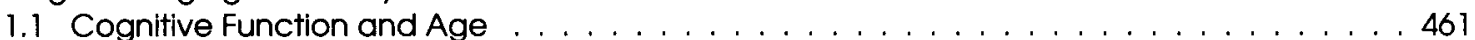

1.2 Cognitive Decline: When and at What Rate? . . . . . . . . . . . . . . . . . 461

1.3 Health-Related Factors and Biological Life Events . . . . . . . . . . . . . . . . . . . . 462

1.4 A Summing Up: What is Normal Cognitive Aging? . . . . . . . . . . . . . . . . . . . . . . 463

2. Pathological Cognitive Aging: Concepts and Diagnostic Criteria . . . . . . . . . . . . . . . 464

2.1 The Borderline Between Normal and Pathological Cognitive Aging . . . . . . . . . . . . . 464

2.2 Rationale of the Need for Early Diagnosis of Dementia . . . . . . . . . . . . . . . . . . 465

2.3 Clinical Characteristics of the Prodromes of Dementia . . . . . . . . . . . . . . . . . 465

2.4 Definitions . . . . . . . . . . . . . . . . . . . . . . . . . . . . . 466

2.5 The Classification of Mild Cognitive Syndromes . . . . . . . . . . . . . . . . . . . . . . . . 467

2.5.1 Benign Senescent Forgetfulness and Malignant Senescent Forgetfuiness . . . . . . . 467

2.5.2 Age-Associated Memory Impairment . . . . . . . . . . . . . . . . . . . . . . . 467

2.5.3 Mild Cognitive Changes (Subthreshold) and Cognitive Impairment Disorders . . . . . 468

2.5 .4 The Global Deterioration Scale . . . . . . . . . . . . . . . . . . . . . . . . 468

2.5 .5 The Clinical Dementia Rating Scale . . . . . . . . . . . . . . . . . . . . . . . .468

2.5.6 The Cambridge Mental Disorders of the Elderly Examination . . . . . . . . . . . . . 469

2.6 Comparison of the Different Criteria for Mild Cognitive Syndromes . . . . . . . . . . . . . . . 469

3. Noncognitive and Behavioural Dysfunction in Borderline States . . . . . . . . . . . . . . . . . . 470

3.1 Subjective Cognitive Complaints as an Early Marker of Dementia . . . . . . . . . . . . . . 470

3.2 Noncognitive Problems in Borderline States . . . . . . . . . . . . . . . . . . . . . . . 470

3.3 Age and Comorbidity . . . . . . . . . . . . . . . . . . . . . . . . . 471

4. Implications for Drug Therapy . . . . . . . . . . . . . . . . . . . . . . . . . 471

4.1 The Impact of Cognitive Aging Research . . . . . . . . . . . . . . . . . . . . . . . . . . 471

4.2 Pharmacological Studies of the Treatment of Alzheimer's Disease . . . . . . . . . . . . . . 472

4.3 Towards the Prevention and Treatment of Cognitive Disorders . . . . . . . . . . . . . . . . . 473

5. Conclusion . . . . . . . . . . . . . . . . . . . . . . . . . . . . . 475

\section{Summary}

The consequences for cognitive functioning of normal aging, depression and dementia are well known. However, the borderline between normal and pathological cognitive aging is less well understood. Recently, it has been found that 
it is important to differentiate between 'successful', 'usual' and pathological cognitive aging. This article reviews existing views on this borderline.

Recently, it has been found that health-related factors, or biological life events, may determine the rate of cognitive aging. Various different, but similar, diagnostic descriptions of age-related cognitive dysfunction exist simultaneously: benign senescent forgetfulness, malignant senescent forgetfulness, age-associated memory impairment, age-consistent memory impairment, late-life forgetfulness, mild cognitive changes (subthreshold) and cognitive impairment disorders are some examples of different diagnostic categories. There are also various diagnostic tools to obtain these experimental diagnoses; for example, the Global Deterioration Scale, the Clinical Dementia Rating Scale and the Cambridge Mental Disorders of the Elderly Examination. A diagnosis is considered important for the early detection of dementia.

Pharmacological treatments are still in the experimental stage. Improvement of cognitive function has particularly been studied in clinical trials with groups of patients with Alzheimer's disease as well as patient groups with age-associatei memory impairment. Future strategies may orient more towards treating symptoms of cognitive dysfunction, probably also on the basis of diagnosis of healthrelated factors, in age-related cognitive decline and depression.

Decreased cognitive function is regarded as an inevitable consequence of advancing age. The majority of healthy elderly people complain about forgetfulness and decreased concentration, and this compromises their quality of life. ${ }^{[1]}$ These complaints are based upon objective changes in cognitive function; it is well established that virtually all aspects of cognitive functioning deteriorate with age. ${ }^{[2-5]}$ However, not all individuals show the same rate of decline; the variability of performance in cognitive tests increasing with age.

Not only does the physiological aging process influence cognition in the elderly, but various biological factors, such as medical conditions, also have an effect. There is a borderline between socalled 'normal cognitive aging' and pathological conditions such as Alzheimer's disease (AD) which are characterised by memory problems and cognitive dysfunction. ${ }^{[6]}$ Great progress has been made in our understanding of particular brain changes in elderly patients with cognitive deficits or $\mathrm{AD}$, and in our understanding of the basal mechanisms of drug action in the brain. There has also been a rapid increase in the interest of clinicians, researchers and the pharmaceutical industry in the development of new classes of drugs for the palliative treat- ment of age-related cognitive deficits and dementing conditions. ${ }^{\text {[7-9] }}$

However, a breakthrough in the pharmacological treatment of these conditions does not seem to be at hand. There are several reasons for the lack of progress in this respect. First, the clinical diagnosis of $\mathrm{AD}$ and related conditions appears to be difficult, especially differentiating these conditions from 'normal' cognitive aging in the early phases of disease. ${ }^{[10]}$ Secondly, there is a lack of information concerning possible prodromes of AD in a phase in which there is a memory problem but not yet frank dementia, and longitudinal studies are sparse. Thirdly, experimental drug research in patients $v$. are not demented and thus do not have a clearly defined medical condition has until now been less popular than drug research in patients with AD. Yet, treatment of patients with cognitive decline in a phase in which the severity of the cognitive deficit is not too profound may bear more promise than treatment of patients with frank dementia.

This article reviews the existing knowledge with respect to the borderline between normal aging and dementia with the aim to describe the domain where future drug trials should be directed. We will describe the current knowledge about so- 
called 'normal' cognitive aging (section 1) and the borderline between normal aging and pathological aging, especially with respect to cognition in the elderly (sections 2 and 3). Implications for future drug development for the treatment of cognitive aging are described in section 4 .

Because the focus of this article is on the borderline, there will not be an in-depth description of neurocognitive decline with age..$^{[1,11,12]}$ Reviews of cognition in dementia can be found elsewhere, ${ }^{[12-15]}$ as can reviews about the pharmacological treatment of patients with dementia. ${ }^{[16-19]}$ An overview of drug treatment studies in relation to cognitive

- ing will be published in a forthcoming issue of tu1s journal. ${ }^{[20]}$

\section{Cognitive Aging in Healthy Individuals}

\subsection{Cognitive Function and Age}

There is vast literature on the relationship between age and cognitive performance. It is now generally agreed that healthy individuals are characterised by cognitive decline during the later decades of adult life..$^{[4,12,21]}$ The acquisition of new information becomes less efficient, which, coupled with a diminished retention of this information, results in substantially poorer memory performance. ${ }^{[1]}$ The ability to plan new activities, solve problems and make complex decisions is noticeably diminished. ${ }^{[22]}$ In addition, attentional pro-

sses appear to be invariably poorer in older pauents than in younger ones. ${ }^{[23]}$

Over a third of all individuals aged over 60 years complain of sleep disorders. ${ }^{[24]}$ Sleeping is closely related to arousal, which is also impaired in old age. In addition, there appears to be a general cognitive slowness, appearing especially in the performance of tasks that have to be carried out under time pressure and/or in demanding situations. A general slowing down of CNS functioning may be the cause of this problem. ${ }^{[3]}$

A fruitful model for this slowing is provided by the notion of resources and resource reduction, as discussed by Salthouse. ${ }^{[25]}$ Briefly, any cognitive activity requires resources, which may be time, space or energy. A reduction of resources results in a diminished capacity to process information. For a thorough overview of the evidence on this issue, the reader is referred to the excellent surveys by Birren and Schaie ${ }^{[21]}$ and La Rue. ${ }^{[12]}$

While it is quite clearly established that elderly people (i.e. over 65 years of age), show a deterioration in cognitive functioning or cognitive efficiency, there is also evidence that this deterioration may start in middle age (around the age of 40 years). It has been found that the performance of even healthy people has already deteriorated by middle-age, at least in some categories of cognitive tests. ${ }^{[26,27]}$ Age-related cognitive problems may lie dormant for decades and only become gradually or suddenly apparent as the patient realises that some aspect of his or her functioning is no longer what it used to be.

Loss of neurons in the CNS may occur as early as the fourth decade of life. ${ }^{[28]}$ Problems that people aged 40 to 60 years experience may have to do with the fact that cognitive functions and abilities deteriorate, giving rise to defective memory function, decrease of cognitive energy, especially in demanding situations, and lack of concentration and attention. These problems often arise at work and can cause problems in family and other relationships, resulting in an increased use of the social security system, healthcare facilities and drugs. The problems of middle-aged people in their work or social relationships are usually ascribed to social causes, but they might also be the consequence of decreased cognitive functioning.

Emotional changes may occur in the elderly, either due to social or material losses, or as a consequence of the knowledge that many faculties have been lost or are diminished. ${ }^{[3]}$

\subsection{Cognitive Decline: \\ When and at What Rate?}

There are 2 competing theories relating to the evolution of cognitive changes. ${ }^{[27]}$ The continuous decline hypothesis states that the decline starts early in life and gradually goes on or accelerates 
with age, whereas the terminal drop hypothesis ${ }^{[29,30]}$ implies that the decline manifests itself abruptly. Terminal drop may occur after a major event, e.g. related to physical health such as an infective disease, resulting in a sharp decrease in cognitive performance. Of course, terminal drop is more likely to occur in the second half of the life span, but because life expectancy has become much longer during the last century, this period can extend over the fourth to the ninth decades of life.

Unfortunately, the majority of cognitive aging research performed until now has focused on performance differences between young adults (mostly students) and elderly patients. As a consequence, there is little information about cognitive deterioration in middle-age, although some work has been done in this area. ${ }^{[31,32]}$ Studying individuals aged between 30 and 60 years is essential to gain insight into functional development during adulthood and to obtain knowledge about which functions decline when.

In this respect it is important to discern individual and group norms. As most studies of cognitive aging are cross-sectional (i.e. studying two or more age groups at one point in time), there is a distinct possibility that studies reporting gradual cognitive decline are merely an artefact of the older age groups containing more individuals who perform poorly. ${ }^{[27]}$ This could be because more elderly than younger individuals are in the period between terminal drop and death. This number increases with group age, causing the average group performance to be poorer. Incidentally, this would also result in higher group variance, a phenomenon often encountered in cross-sectional research. Individual age-performance trajectories, as Rabbitt and Goward ${ }^{[33]}$ put it, may differ widely and yet result in a steadily declining overall trajectory.

Another possibility is that most individuals do indeed show a gradual decline with age, perhaps as a result of the accumulation of effects of minor brain dysfunction. ${ }^{[26,32]}$ At first, these minor pathologies may have little impact but, as they accumulate with advancing age, their amassed effects result in perceivable cognitive deficits. Terminal drop would then only occur as a result of some major pathology.

This latter possibility is clearly the more optimistic one, as it paves the way for adding life to the years. As yet, we do not know which of the two possibilities, or some combination, might apply.

Does continuous decline or terminal drop exist to a comparable extent for all different cognitive functions? This is unlikely, as it is known that even memory is not a unitary function and particular aspects of memory, e.g. recognition memory, appear to remain relatively intact in later life. ${ }^{[34]}$ The decline of sensory and perceptual performance ${ }^{[35]}$ and physical performance ${ }^{[36]}$ can have great imf on general cognitive functions, but there need not be any direct or causal relation to cognitive performance. Any loss of memory may well lag very much behind perceptual loss, or not occur at all. Likewise, 'executive function' appears an important mediator of age-related dysfunction, as it has been shown that after correction for executive function, age was not a predictor for test performance.

\subsection{Health-Related Factors and Biological Life Events}

With regard to the question of what factors might influence cognitive decline apart from chronological age, there is increasing interest in the factor of health. Up to a few years ago there were no reports on the influence of health-related factors on age-related cognitive decline. Of course, cognitive dysfunction in relation to well established dise states such as brain trauma, depression and alcohorism are well documented. However, the issue at stake is whether conditions with an unknown or ambiguous relationship with cognitive (dys)function, such as very mild closed head injury, social drinking, borderline hypertension, anaesthesia or diabetes mellitus, have some influence on cognitive functioning.

Recently, the term biological life events (BLE) was proposed to define 'those factors that are related to physical or mental health, experienced at any point in life and thought to be related to brain dysfunctioning, other than grossly impairing con- 
ditions like dementia and brain trauma' ${ }^{[26,32,37,38]}$ BLE are factors with potential, but until now unproven, influence on the brain. Mild head trauma, operation under general anaesthesia and history of alcohol (ethanol) consumption are examples of BLE. We have shown that the performance on particular memory tests does not decrease with age until 80 years of age in BLE-free patients, whereas performance in BLE patients is seriously compromised from the age of 60 years. ${ }^{[38,39]}$ Follow-up research showed that elderly patients with memory disorders have experienced BLE in their life significantly more often than matched controls. ${ }^{[32]}$

thermore, they are more characterised by soft indices of brain dysfunction such as primitive reflexes. ${ }^{[40]}$

Recently, researchers have called for more extensive population-based studies in which the complex interplay between health and cognition would be investigated, as well as the natural history of cognitive performance and change, in order to identify environmental factors associated with cognitive preservation or deterioration. ${ }^{[41,42]}$ Interestingly, Haxby et al. ${ }^{[43]}$ have already found that the effects of age on visual memory were much smaller than those usually reported in the literature after 'rigorous health screening' of the patients studied. Likewise, Christensen et al. ${ }^{[44]}$ provided evidence in favour of the notion that careful assessment, selection and description of patients, as well as further attention to health status, is needed to aid interpre-tion of cognitive aging research.

Other possible health-related factors which may influence cognitive aging are mild hypertension, ${ }^{445]}$ medication and exposure to neurotoxic factors. ${ }^{[38,46]}$

Subtle health-related factors are potentially important to cognitive aging. We assume that they are not severe enough to cause any acute or perceivable trouble for the individual, but that they still have some long term impact on brain functioning and cognition. Thus, although the patient is considered to have recovered, it is likely that the brain has suffered some functional damage which cannot be diagnosed. This suggests that healthy individuals with BLE may be on the border between normal and pathological aging, and are more vulnerable to accelerated cognitive decline.

An additional problem in cognitive aging research is that the tests that are used for neuropsychological assessment of the elderly are characterised by a lack of norms for the majority of the relevant tests. Normative data, which take healthrelated factors and education into account, are as yet nonexistent. However, in order to differentiate normal age-related functional decline from pathological functional decline, we have to know how healthy adults of all ages perform the test used to evaluate the function. Furthermore, as there may be interactions in effects on performance between age on the one hand, and sex, education and health variables on the other, age norms should ideally be based on data obtained from various subgroups within a given age category. Lack of properly divised tests with good norms and in-parallel versions is also quite an impediment for the proper execution of drug trials aimed at treatment of cognitive decline. ${ }^{[47]}$

\subsection{A Summing Up: What is Normal Cognitive Aging?}

The finding of large interindividual differences in a group of patients who can be regarded as normal by any standard used in the experimental literature raises the issue of normality. ${ }^{[26,32,38]}$ Usually, an operational, statistical definition of normality is used; observations are regarded as normal if they fall within some fixed boundaries, for instance in the middle $90 \%$ of their range.

Rowe and Kahn ${ }^{[48]}$ stressed in their theoretical review of aging that the variability of a given parameter, for instance performance on a memory test, increases with age. The authors paid attention to the heterogeneity even in normal groups, i.e. disease-free groups of elderly people. They argued that a distinction should be made between 'successful' and 'usual' aging. Successful aging refers to changes that are intrinsic to age itself, whereas usual aging is the result of aging plus all nonpathological deficiencies that occurred earlier in life. These deficiencies are not intrinsically related 
to the process of aging per se but they are closely associated with aging because their effects are greater in old age (due to increased vulnerability or reduced resistance) ${ }^{[32,38]}$ In addition, the chance of being affected by these deficiencies increases with age.

The notion of the normality of usual aging implies the harmlessness of several possibly healththreatening factors, such as BLE. Normality also implies that what is usual is also natural and cannot, or should not, be modified. This notion of 'normality' puts too much emphasis on the level of functioning of most elderly individuals, instead of attempting to explain the reason for the increased heterogeneity. 'It tends to create a gerontology of the usual'. [48]

Stones et al. ${ }^{[49]}$ have identified 4 different types of aging (see table I). With this model of multiple types of aging, it becomes understandable why age-associated decline can accelerate and why the variability increases with age, 2 trends often observed in aging research. The frequency of aging types 2 to 4 must increase with age, as these agelinked conditions and processes are irreversible in most cases, and any brain dysfunction that is caused by them is likely to be permanent. The onset of these age-extrinsic conditions can be assumed to vary between individuals. The aggregated deleterious effects of pathology or lifestyle on the average performance in a random sample of patients is therefore expected to accumulate with age. Conversely, processes that are age-intrinsic (primary aging) are more likely to cause a linear decline of cognition with age, if a given function is to decline at all as a result of primary aging.

It has been hypothesised that BLE constitute a biological substrate for nonpathological deficiencies that are associated with usual aging (type 2). ${ }^{[38,39]}$ Subdivision of patients based on whether they have a history of BLE can be equated to the distinction between successful and usual aging, i.e. between aging types 1 and 2 . This hypothesis should be investigated further in the light of the fundamental issue about when age-associated changes can be regarded as age-intrinsic, i.e. phys-
Table I. Types of aging

\begin{tabular}{ll}
\hline Type & Characteristics \\
\hline $\begin{array}{l}\text { Primary (or successful) } \\
\text { aging }\end{array}$ & Functional changes intrinsic to age \\
Usual aging & $\begin{array}{l}\text { Nonpathological deficiencies added to } \\
\text { the age-intrinsic processes of } \\
\text { successful aging } \\
\text { Pathology-related decrements added } \\
\text { to nonpathological aging }\end{array}$ \\
Secondary aging & $\begin{array}{l}\text { Pathological aging plus the effects of } \\
\text { terminal illness. Tertiary aging can } \\
\text { thus be roughly equated to the }\end{array}$ \\
& $\begin{array}{l}\text { terminal drop' phenomenon } \\
\text { t30] }\end{array}$ \\
\hline
\end{tabular}

iological, and when the aging process is usual but disease-free.

\section{Pathological Cognitive Aging: Concepts and Diagnostic Criteria}

\subsection{The Borderline Between Normal and Pathological Cognitive Aging}

The borderline described in the preceding sections is especially relevant in relation to dementing conditions and their prodromes. The most common form of dementia is $\mathrm{AD}$, which accounts for 50 to $70 \%$ of all cases of dementia. It is evident that an insidious and progressive disease such as AD does not manifest itself from the very beginning as the complete syndrome of dementia. Early in the course of $\mathrm{AD}$, the patient may exhibit mild memory $\mathrm{in}$ pairment and changes in other mental domains that are not sufficiently severe to merit the diagnosis of dementia. Recognising these prodromes of dementia is one of the most complex diagnostic problems to date.

This section summarises what is known about this 'grey area'. Definitions of dementia and AD are given to show the vague boundary between dementia and non-demented conditions; this is especially relevant because there is no uniformity in assessment strategies and classification systems with regard to the borderline. 


\subsection{Rationale of the Need for Early Diagnosis of Dementia}

From a scientific point of view, the diagnosis of 'early' AD helps to clarify epidemiological aspects such as the natural history of the disease, which is of major importance for planning and developing healthcare facilities. The lack of clear diagnostic criteria for early $\mathrm{AD}$ is reflected by the estimates of its prevalence. In contrast to severe dementia, in which the prevalence is remarkably consistent in various studies (about $5 \%$ of the population over 65 years of age), the prevalence of mild dementia $r$ 'ges from $2.6^{[50]}$ to $21.9 \%$, and even up to $52.7 \%$ 1. une Japanese study. ${ }^{[51]}$ The main reason for this extreme variation is probably differences in the criteria and methods used to identify mild dementia $^{[51,52]}$ and problems with regard to the definition of the boundary between normal aging and pathological conditions.

From a clinical point of view, the need for an early diagnosis is also of vital importance. A significant minority of patients with the diagnosis of dementia have treatable conditions, ${ }^{[53-56]}$ and treatment of these diseases is expected to be more successful in the early stages ${ }^{[57,58]}$ before changes in the brain have become structural. ${ }^{[19,59]}$ In addition, it is of great importance to have diagnostic methods which accurately differentiate those patients with mild dementia from those with more benign forgetfulness, because of the public's growing awareness of dementia as a major health problem

1 the corresponding anxiety associated with this awareness. ${ }^{[60-63]}$

\subsection{Clinical Characteristics of the Prodromes of Dementia}

The onset of $\mathrm{AD}$ is often dated in retrospect and with imprecision. Information from relatives can provide a lot of insight into the very first prodromes but these data are largely anecdotal. Typically, predemented patients demonstrate feelings of anxiety, worry, depression and psychological vulnerability although these feelings are less pervasive than those in patients with major depres- sion. ${ }^{[64-66]}$ Inner feelings may be more dependent on environment: patients become calm when reassured, but they may be unable to cope with even a small amount of stress. ${ }^{[64,65]}$ Passivity, loss of interests, and coarseness may be common features. Patients appear less spontaneous and extroverted, and more withdrawn.

Some features of this syndrome reflect disruption of compensating abilities, such as a tendency to tire easily and difficulty adjusting to events that are not part of a daily routine, whereas other features are more likely to be secondary phenomena, such as withdrawal, anxiety and a tendency to worry ${ }^{[65,67-70]}$ Although the predemented patients themselves may not notice these changes, their relatives probably do. ${ }^{[71,76]}$

This picture of 'predementia' or prodromes of dementia should be regarded as tentative. It is not known if all patients with AD present with a similar picture to the one described here. Moreover, we do not know the predictive value of predementia. To date, no clear diagnostic categories adequately classify this clinical picture. The patient's state may be too subtle to be described in reliable research criteria. Aqualitative approach, i.e. a detailed psychopathological description, is probably the most adequate approach. The importance of a qualitative assessment is underlined by the relative lack of specificity of the traditional psychometric tests. ${ }^{[15]}$

Neurological examination probably does not reveal any abnormalities, nor do ancillary data such as those obtained from laboratory or neuro-imaging investigations, ${ }^{[77,78]}$ although there may be an increase in 'soft' neurological signs early in the course of illness. ${ }^{[40]}$ The patients may perform within normal ranges on traditional psychometric tests of memory, but may need more time to complete tasks and show a tendency to tire and slow down when testing takes too long. ${ }^{[13,15,51,79]}$

If memory is impaired, this can usually be identified by tasks measuring delayed recall. ${ }^{[64,65,79,80]}$ With respect to the search for biological markers to distinguish between $\mathrm{AD}$, and normal and borderline states, until now none of these markers has proven successful in individual patients given the 
findings obtained by computed tomography (CT), ${ }^{[81]}$ single photon emission computed tomography $(\mathrm{SPECT})^{[82]}$ and magnetic resonance imaging (MRI) ${ }^{\left[{ }^{[3,84]}\right.}$ Given the lack of reliable and valid aetiologically based objective tests, the diagnosis of early AD is still based on detailed clinical description, differentiation from normality and other behavioural diagnoses (e.g. depression), neuropsychological examination, and follow-up studies. ${ }^{[74,85,86]}$

\subsection{Definitions}

Considerable progress in the accurate diagnosis of dementia has been made in the last decade. Consensus procedures have yielded operational criteria for the clinical diagnosis of dementia and the main dementing illnesses. ${ }^{[87-90]}$ Although dementia is now generally regarded as a clinical syndrome and not as a disease, important differences exist in the interpretation of this notion.

The term dementia is used by some researchers to denote a clinical condition defined only by observable behaviour, irrespective of its aetiology. For instance, in the National Institute of Neurological and Communicative Disorders and Stroke and the Alzheimer's Disease and Related Diseases Association (NINCDS-ADRDA) criteria for clinical AD states it is proposed that 'dementia is a diagnosis based on behaviour and cannot be determined by computerised tomography, electroencephalography, or other laboratory instruments, although specific causes of dementia may be identified by these means' ${ }^{\cdot{ }^{89]}}$ The consequence of this definition is that dementia can be caused by both organic and functional disorders.

Other researchers limit the definition of dementia to organic aetiologies. For instance, the DSMIV states that 'either there is evidence ... of specific organic factor(s) judged to be aetiologically related to the disturbance, or, in the absence of such evidence, an aetiological factor can be presumed if the disturbance cannot be accounted for by any nonorganic mental disorder, e.g. major depression accounting for cognitive impairment' ${ }^{[91]}$ Still, others have extended the definition of dementia to in- clude characteristics of irreversibility or a progressive course. ${ }^{[92]}$

The most widely used definitions of dementia to date are those of the DSM-III-R and DSM-IV. ${ }^{[87,91]}$ In short, the DSM definition involves a combination of memory impairment with impairment in at least one of the domains of abstract thinking, judgement, aphasia, apraxia and agnosia, constructional difficulty, or deficits in executive function. The impairment must be severe enough to interfere with social functioning. It is important to note here that the DSM-IV definition implies the acceptance of some degree of heterogeneity; not all cognitive domains are necessarily affected. Virtually all c rent research studies make use of the DSM-IV criteria, except for the last criterion concerning the presumed organic aetiology.

With respect to criteria for the diagnosis of $A D$, 2 sets are widely used: the DSM-IV criteria for Primary Degenerative Dementia of the Alzheimer type (PDD) ${ }^{[91]}$ and the so-called NINCDS-ADRDA criteria. ${ }^{[89]}$ The latter criteria are comparable with those of the DSM-IV, but are more elaborate and better operationalised.

The NINCDS-ADRDA criteria differentiate between possible, probable and definite $A D$. A diagnosis of definite $A D$ can only be made when the criteria for probable $A D$ are fulfilled and when there is histopathological evidence from biopsy or autopsy. Probable AD is defined by the presence of dementia, an onset between 40 and 90 years of age, and the absence of systemic disorders that the selves could account for progressive deficits in me ory and cognition. A diagnosis of possible $\mathrm{AD}$ is made when there are variations in onset, presentation, clinical cause or in the presence of a second possible dementing disorder, which is clinically not considered to be the course of dementia. Allowance is made for plateaus in the course of progression or in the presence of associated psychiatric, somatic or neurological symptoms.

The most widely used clinical criteria for vascular dementia are those of the DSM, based on clinical description. The features are not defined in detail and leave much room for interpretation. 
Ischaemic scales have long been used for the diagnosis of vascular dementia. ${ }^{[33,94]}$ More recent criteria have also paid attention to the temporal relationship between dementia and stroke, the number of strokes, and brain imaging data. ${ }^{[88,90,95,96]}$

\subsection{The Classification of Mild Cognitive Syndromes}

The differentiation between dementia and normal states has been especially problematic. In the past 30 years, several attempts have been made to define the clinical and neuropsychological features

he borderline state between normality and frank dementia. As early as $1958, \mathrm{Kral}^{[97]}$ introduced the terms benign and malignant senescent forgetfulness (BSF and MSF) to describe memory complaints of the elderly people he studied. Since then, investigators have tried to describe these states in more detail, e.g. very mild or mild cognitive decline, ${ }^{[98]}$ questionable dementia, ${ }^{[99]}$ minimal dementia, ${ }^{[92]}$ age-associated memory impairment (AAMI), ${ }^{[100]}$ age-consistent memory impairment and late-life forgetfulness. ${ }^{[101]}$ In addition, the DSMIV includes a new category, age-associated cognitive decline. ${ }^{[102,103]}$ However, the nosological status of many of these proposals is still unclear, especially regarding the extent to which they are related to dementia. ${ }^{[104]}$

Nevertheless, the concepts provide a good starting point especially because clear and unequivocal diagnostic criteria are a prerequisite for developint of therapeutic strategies for patients with cognitive complaints. The main concepts are described below.

\subsection{Benign Senescent Forgetfulness and Malignant Senescent Forgetfulness}

The concepts of BSF and MSF were introduced more than 30 years ago and probably represent the earliest attempt to distinguish clinically between normal age-related memory changes in the elderly and those forms of memory change with a worse prognosis. ${ }^{[97]}$ The terms have often been used in the medical literature and have become a generally accepted notion among clinicians.
The presentation of BSF is ' . . patchy and variable, with difficulties remembering details of experiences (names and places), but with relative ease in recalling the experiences itself. Usually, the forgotten details are recalled later' ${ }^{\text {[97] }}$ The condition is not progressive and does not increase the risk of developing dementia. In contrast, MSF is characterised by an inability of the patient to recall events in the recent past, disorientation with regard to personal data, and retrogressive loss of remote memories. Patients with MSF remain unaware of their deficit and frequently produce confabulations.

BSF and MSF were never appropriately defined in operational terms. As a consequence, research data on the reliability of the criteria are sparse; few data exist on the prognostic value of BSF. Kral carried out a 4-year follow-up study with 20 patients with BSF and 34 with MSF; only 1 patient with BSF deteriorated cognitively, whereas all patients with MSF did. ${ }^{[105]}$ Death rates in BSF and MSF also differed significantly from one another: $38 \%$ vs $61.7 \%$, respectively, after a 4-year observation period. Recently, a 3-year follow-up study of patients with supposed BSF was reported by O'Brien et al. ${ }^{[74]}$ : 6 of the 68 patients with BSF (9\%) became demented, which was about twice the expected rate. These findings cast doubt on the view that BSF always follows a benign course. Because of the ill-defined criteria and their uncertain nosological status, the use of the terms BSF and MSF cannot be recommended for research and clinical purposes, in spite of their widespread popularity.

\subsubsection{Age-Associated Memory Impairment}

The term AAMI was introduced by Crook et al. ${ }^{[100]}$ and denotes a condition in otherwise healthy middle-aged or elderly individuals (50 years or older) who complain about memory loss and who score at least 1 standard deviation (SD) from the mean for younger adults on neuropsychological tests of secondary memory. The AAMI criteria were provisionally established in order to have an operational definition of 'normal' cognitive aging. In relation to the discussion on 'normality' in section 1.7, AAMI is partly associated with usual 
aging and partly with secondary aging. In addition, patients who are in the prodromes of dementia may be diagnosed with AAMI.

Blackford and LaRue ${ }^{[101]}$ criticised certain aspects of the AAMI concept, including the omission of an upper age limit, the omission of any means of quantification of subjective complaints, the criterion that 'performance is $1 \mathrm{SD}$ below the mean established for young adults on a standardised test for secondary memory' (which precludes the use of tests developed especially for old-aged populations), and the likelihood of meeting the above-mentioned criterion when more tests are administered. Besides, the AAMI criteria provide a minimum for the deviation in memory performance (at least $1 \mathrm{SD}$ ), but no maximum, although dementia should be ruled out.

Blackford and LaRue ${ }^{[101]}$ added to AAMI the following new categories: age-consistent memory impairment (ACMI) for performance within $1 \mathrm{SD}$ of the mean established for age on $75 \%$ or more of the tests administered, and late-life forgetfulness to denote performance between 1 and 2 SD below the mean established for age on $50 \%$ or more of the tests administered.

Data on the reliability and validity of the AAMI criteria have not been published yet. Furthermore, no longitudinal data have been reported and, therefore, the prognostic significance of the AAMI concept remains unsettled. The use of the term AAMI in clinical practice is limited. Nevertheless, the criteria are well defined operationally and provide a basis for selecting study participants in order to study the epidemiology, course and clinical significance of normal aging, and to evaluate the effect of pharmacological or other forms of intervention. ${ }^{[106,107]}$ More refined criteria have been proposed which may make the AAMI concept, in a revised form, more fruitful for clinical use. ${ }^{[108]}$

\subsubsection{Mild Cognitive Changes (Subthreshold) and Cognitive Impairment Disorders}

The DSM-IV includes a new category of 'mild cognitive changes (subthreshold)' as part of the class of cognitive impairment disorders. ${ }^{[103,109,110]}$ In contrast to the DSM-III, the DSM-III-R speci- fies the severity of dementia in terms of functional capacity. ${ }^{[87]}$ The prognostic value of the DSM-III criteria for the mildest stages of dementia is high when applied by experienced clinicians in selected patient groups. ${ }^{[111,112]}$ In field studies, however, the criteria seem to be less accurate. ${ }^{[13]}$

\subsubsection{The Global Deterioration Scale}

In 1982, Reisberg and co-workers ${ }^{[98]}$ presented the Global Deterioration Scale (GDS) for the grading of primary degenerative dementia. The GDS is one of the most widely used clinical instruments to stage the course of cognitive decline and AD. The scale describes cognitive and behavioural changes in 7 stages.

- Stage 1 describes 'normality' (no complaints, no deficits).

- The description of stage 2 ('very mild cognitive decline') is rather nonspecific.

- The characteristics of stage 3 ('mild cognitive decline') are more specific, but they refer almost exclusively to memory or related cognitive domains.

- From stage 4 onwards the DSM-III criteria for dementia are amply met.

The prognostic properties of the various stages are reasonably established. Generally, GDS stage appears to be a major predictor of decline: patients in stage 2 have a low risk of declining in the following years, whereas a large proportion of the patients in stage 3 and more so in stage 4 show cognitive decline. It has been suggested that a GDS score of 2 reflects normal aging (i.e. 'usual' aging in terms of the earlier discussion) in practically patients, whereas GDS stage 3 represents borderline cognitive functioning. From stage GDS 4 onwards, a progressive course of decline is likely. ${ }^{[98]}$

\subsubsection{The Clinical Dementia Rating Scale}

The Clinical Dementia Rating Scale (CDR) ${ }^{[99]}$ rates the severity of dementia as questionable, mild, moderate or severe (scores of $0.5,1,2$ or 3 , respectively. The individual performance is rated separately in each of the categories of memory, orientation, judgement and problem solving, community affairs, home and hobbies, and personal care. From these ratings, an overall CDR score is calcu- 
lated according to a complicated algorithm. The criteria carry high face validity and are based on a wide range of cognitive activities in daily life. Memory performance in daily life is considered to be the central criterion, while the other features are regarded as secondary.

Interrater reliability and construct validity of the CDR have been demonstrated. ${ }^{[14]}$ The scale has been documented by several longitudinal studies, which make the CDR probably the besttested rating scale for staging dementia to date..$^{[115]}$ The CDR is considered to be a well-documented scale for rating dementia in selected samples. The

le is more difficult to administer than the GDS. From CDR stage 1 onwards a deterioration of $\operatorname{cog}$ nitive functioning can be reliably predicted, whereas CDR stage 0.5 reflects the borderline state. ${ }^{[99]}$

\subsubsection{The Cambridge Mental Disorders of the} Elderty Examination

The Cambridge Mental Disorders of the Elderly Examination (CAMDEX) consists of a standardised psychiatric interview with the patient and caregiver, and a brief neuropsychological battery (the CAMCOG). ${ }^{[92,116]}$ The CAMDEX was especially designed for the detection of early dementia and describes 4 syndromes as guidelines for the staging of dementia: minimal, mild (early), moderate and severe dementia. In contrast to the GDS and the CDR, the CAMDEX can be used to obtain a syndromal and aetiological diagnosis. The CAMDEX

'teria should be used in a 'flexible manner', leav$11 \mathrm{~g}$ 'some room for clinical judgement' ${ }^{[116]}$

The face validity of the CAMDEX is high and the interrater reliability is good. ${ }^{[92]}$

In some recent studies of longitudinal followup design in which the CAMDEX was used to assess patients, it was concluded that, although the CAMDEX criteria were in general feasible, the criteria for minimal dementia were difficult to apply in clinical practice. ${ }^{[117,118]}$ Errors in the diagnosis of minimal dementia occurred, especially in people of below-average intelligence, in the old and frail, and in patients with sensory impairments. The need for repeated assessments over lengthy periods was stressed in order to document the natural history of dementia correctly.

\subsection{Comparison of the Different Criteria for Mild Cognitive Syndromes}

Comparison of the different concepts and criteria discussed above shows that there is considerable overlap in clinical characteristics. At the outset, there are few differences between Kral's BSF and Reisberg's very mild cognitive decline (GDS stage 2). Likewise, stage 3 of the GDS closely resembles the description of very mild cognitive impairment of the CDR (CDR score of 0.5) and the CAMDEX definition of minimal dementia, whereas GDS stage 4, CDR stage 1 and CAMDEX mild dementia are all highly compatible with the criteria for mild dementia as defined by DSM-III-R. However, the concepts differ, ${ }^{[119,120]}$ and thus the comparison of the results of these studies should be approached with some caution.

From the results of the follow-up studies on the prognosis of early $\mathrm{AD}$, as defined by the different criteria, it can be concluded that the likelihood of further cognitive decline is low (but not zero) for patients with mere memory complaints classified as BSF or GDS stage 2; intermediate for patients with questionable dementia, GDS stage 3 or CAMDEX minimal dementia; and high for patients with GDS stage 4, DSM mild dementia, CAMDEX mild (early) dementia and CDR stage 1. Stated in another way, patients who complain only about poor memory, without objective evidence of impaired memory and who perform well in daily activities cannot be regarded as being at high risk of developing dementia. In contrast, those who demonstrate objective cognitive impairments that interfere with social functioning probably will develop dementia.

It should be considered that these studies were performed with selected samples. It is still impossible to accurately predict the outcome in individuals with mild cognitive changes. 


\section{Noncognitive and Behavioural Dysfunction in Borderline States}

\subsection{Subjective Cognitive Complaints as an Early Marker of Dementia}

With respect to the differentiation of a dementing condition from 'normal' aging, it is important to know whether the judgement of one's own memory (often referred to as metamemory) ${ }^{[121,122]}$ reflects objective cognitive functioning and whether memory complaints have diagnostic meaning. Complaints of memory are quite common in elderly and middle-aged individuals. In fact, in 1 study no less than $73 \%$ of the 40 -year-old patients and $91 \%$ of the 70-year-old patients reported difficulties in remembering. ${ }^{[71]}$

- Although the growing interest of the public media in dementia and AD may have increased the awareness of memory deficits as a possible first sign of mental deterioration, ${ }^{[60-62]}$ much evidence suggests that memory complaints in older adults correlate to a large extent with depression, but only modestly with their performance on objective memory tests. ${ }^{[71,73,123]}$ However, the finding that the association of subjective complaints with depression is stronger than with dementia should not be interpreted too dichotomously, since depression may also be a presenting symptom of AD. ${ }^{[124]}$ Moreover, a recent study reported that relatives' assessments of patients' memory, measured by standardised questionnaires, were a reasonable predictor of dementia, with an overall classification accuracy rate of $74 \%$. This rate was improved by $11 \%$ when objective memory tests were also used. ${ }^{[73]}$

These findings emphasise the diagnostic importance of taking a history from a relative or other informant who can report on the premorbid behaviour of the patient. Because metamemory is a poor predictor of cognitive decline in patients who are already demented, it would be of interest to investigate whether complaints of one's decreasing cognitive functions anticipate manifest dementia.

\subsection{Noncognitive Problems in Borderline States}

There is good evidence that deficits of memory are among the earliest features of AD. ${ }^{[94,112,125]}$ However, this does not mean that impaired memory is a prerequisite for the diagnosis of $\mathrm{AD}$ in its prodromal stage. That which has to be proven is accepted as proof when memory impairment is considered to be the main characteristic of the preceding stages of dementia. ${ }^{[79]}$ Interestingly, a large amount of evidence from epidemiological and descriptive studies shows that noncognitive symptoms are equally prominent in the disintegratior $f$ psychological organisation. These symptoms ...volve perception, motility, personality organisation, emotional experience and volition. ${ }^{[126-128]}$ In addition, the continuum between patients characterised as normal and those with pathological cognitive decline is also found for noncognitive behaviour. For instance, a study of randomly selected women aged from 70 to 79 years yielded a smooth and unimodal distribution of cognitive function and behavioural changes. ${ }^{[129]}$ Recently, Berrios has challenged the view that prodromes of dementia should be defined as a form of 'minidementia', i.e. only differing quantitively from dementia. ${ }^{[126]}$

The most frequently studied noncognitive aspects of early $\mathrm{AD}$ are changes in affectivity and personality. Depression can be related to age-related cognitive decline and prodromes of dementia in several ways: depression may present with the cli cal picture of dementia ('pseudodementia'), $\left.{ }^{\mid 130,}\right)$ ' may coexist with dementia, or depression may precede dementia. ${ }^{[124,131]}$ Furthermore, dementia, notably the subcortical types, can mimic depression, and both conditions may develop independently from one another. ${ }^{[32]}$

The notion of depression being an early manifestation of dementia is still under debate. In a retrospective study, the relatives of patients with $\mathrm{AD}$ reported depression and agitation as being the first symptoms of dementia in about $40 \%$ of the patients. ${ }^{[133]}$ In prospective studies, depressive symptoms in combination with cognitive deficits 
in elderly patients were also found to increase the risk of the patient developing subsequent dementia. ${ }^{[124,131]}$ However, other studies did not report an increased prevalence of depressive symptomatology in patients who subsequently developed dementia. ${ }^{[128,134]}$

The results of these studies have to be evaluated carefully, because the definitions used for depression and dementia may be different from those adhered to today. ${ }^{[86]}$

In summary, patients with depressive symptoms and cognitive deficits may often have prodromes of $\mathrm{AD}$. However, these patients have unfortunately - $n$ rejected from participation in most studies of AN, probably due to a dichotomous view in which depression and dementia are regarded as mutually exclusive. More refined clinical and neuropsychological descriptions and prospective neuroimaging and neurochemical studies should be carried out in order to elucidate the relationship between depressive symptoms and mild dementia.

With respect to studies into personality changes in $\mathrm{AD}$, it has recently been shown that $\mathrm{AD}$ patients become more passive, more coarse and less spontaneous. The personality changes occurred early in the course of the disease and could not be attributed to the decline in intellectual function. ${ }^{\text {69] }}$ Similar profiles (diminished initiative, loss of selfconfidence, decreased extroversion, growing apathy, relinquishment of hobbies, and increased rigidity) have also been found in other studies. ${ }^{[64-68]}$ Many patients had subtle personality changes long

'ore dementia became clinically manifest.

Thus, personality changes are likely to be among the earliest features of AD and are evident in the phase preceding dementia. Although the assessment of personality in patients with dementia presents unusual and difficult methodological problems, personality changes should be seen as a marker of early $\mathrm{AD}$ and warrant further investigation.

\subsection{Age and Comorbidity}

It should be noted that most of the research into AD has been carried out in relatively young, healthy patients even though dementia is more prevalent among the older and more diseased population. Older populations show higher levels of comorbidity. The relevance of this aspect has been noticed in field studies in which particular diagnostic errors in very old patients and those with significant comorbidity were noted. ${ }^{[17]}$

Older patients are more difficult to investigate appropriately. Many of these patients live in nursing homes or other protected environments, where criteria for social and functional decline are harder to meet than in younger patients who are still working. ${ }^{[135]}$ Moreover, samples of older patients will inevitably suffer more from methodological flaws such as higher mortality figures and more loss at follow-up. Therefore, data from studies using relatively young patients cannot be directly applied to a typical geriatric population. It seems likely that the detection of a prodrome of $A D$ and early $A D$ in young, healthy patients requires a different approach to that for older patients. These aspects have generally been neglected so far in research of the borderline between normal aging and dementia, and the earliest stages of AD.

\section{Implications for Drug Therapy}

\subsection{The Impact of Cognitive Aging Research}

Research into cognition in usual aging, AAMI and dementia has a common problem, namely the profound heterogeneity within groups of patients ${ }^{[136]}$ Many health-related factors and disease states, as well as education and psychosocial factors, contribute to the pattern of cognitive and noncognitive deficits and complaints. ${ }^{[137]}$ The clinical syndrome of dementia is heterogenous whereas $A D$ may consist of several different nosological entities. ${ }^{[138,139]}$

Unlike primary aging (see table I), secondary and tertiary aging are associated with other factors in addition to age. As discussed in sections 2.3, 3.1 and 3.2 , the syndrome of complaints and functional deficits in usual aging and in the putative prodromes of dementia are not uniform in the sense that 'only' memory or 'primarily' memory is affected. 
On the contrary, a number of cognitive and noncognitive functions are affected (section 3 ).

This has considerable implications for therapeutic strategies in the field of age-related cognitive deficits. A major point concerns the choice of patient population as a target. Patient groups with AAMI or ACMI may contain quite a number of individuals who have very early $\mathrm{AD}$. Drug treatment of this group may be of relevance in order to prevent or postpone the onset of AD. Another relevant aim may be the treatment of noncognitive behavioural problems in this group (e.g. symptoms of mood disorder or lethargy) as these have an important impact on the functional capacity of the patient and his or her quality of life. A third aim may be the development of strategies for patients who complain of cognitive dysfunction but who may never develop dementia, yet are handicapped in their daily life.

There is increasing evidence that patients who are not demented but who do have objective cognitive deficits on neuropsychological investigation should be characterised as a disease group: the new classification of the DSM-IV, 'age-associated cognitive decline', ${ }^{[102]}$ may improve the possibility of targeting these patients for drug development.

It may be important to discern various subgroups within the heterogeneous group of nondemented patients with impaired cognitive functioning, e.g. those with BLE and those without (see section 1.3). Patient groups for drug studies can be made more homogeneous, which would improve the detection of possible drug effects. The rationale is that the pathogenesis of the cognitive decline can be expected to differ for the various subgroups.

Similarly, it may be of interest to search for drug effects in non-demented elderly people who have an abnormal profile of apolipoprotein E4 (Apo E4), as this substance has been implicated in AD. ${ }^{[140]}$ Likewise, other biological markers could be used to select non-demented individuals with cognitive impairment for experimental drug studies. Measurement of hippocampal atrophy or pupillometry could be relevant in this respect because of findings in recent years, which suggest that patients with hippocampal atrophy ${ }^{[84]}$ or with abnormal pupil reaction to low doses of tropicamide ${ }^{[141]}$ may be individuals in the borderline between normal aging and dementia.

\subsection{Pharmacological Studies of the Treatment of Alzheimer's Disease}

Current research into the effects of experimental drugs in the treatment of $\mathrm{AD}$ and $\mathrm{AD}$-related conditions has met with difficulties. Through the years, it has appeared that the majority of studies have been characterised by methodological flaws. ${ }^{[142]}$ The patient groups tend to be too heterogen $r$. particularly with regard to symptoms and sevel...y, there is a lack of sensitive and reliable evaluation measures, and the length of the treatment period may differ considerably from study to study (see also Hijman et al ${ }^{[47]}$ for discussion). Furthermore, no reference or benchmark drug exists and patients often experience adverse effects in these studies.

The tacrine experience illustrates these problems. Although tacrine has been given the benefit of the doubt by many world markets, ${ }^{[143]}$ it is not registered in several countries, including The Netherlands, because of its adverse effect profile. A $40 \%$ chance of a positive response set against a $60 \%$ chance of severe adverse events is a cost-benefit problem.

Finally, statistically significant results on some psychometric measures are not always reflected by clinically relevant findings. For instance, an improved score on a memory test without a concc $m$ itant improvement in daily life activities is not re? evant from a clinical point of view.

$\mathrm{AD}$ drug studies performed in the last decade have shown that it is not a fruitful strategy to treat $\mathrm{AD}$ as a disorder of memory. Memory is not a unitary function but consists of various subprocesses which are dependent on different neurotransmitters and centres in the brain. Thus, many classes of drug can be used for the treatment of memory disorders. ${ }^{[144]}$ Besides, AD is not a one-neurotransmitter disease; various neurotransmitters are affected and these are related to a variety of cognitive behaviours from memory to problem solving. ${ }^{[145,146]}$ 
Drugs with possible treatment efficacy could thus be based upon an action at various different neurotransmitter systems. This is especially the case because behavioural problems in $A D$ and related conditions such as mood disorders, lethargy, personality changes, anxiety, and in patients with more severe disease, restlessness, wandering, psychosis and aggression require treatment as much as the cognitive problems do. ${ }^{[147,148]}$ Until now, researchers involved in drug development have been disproportionately interested in the cognitive symptomatology.

Finally, there is a lack of research directed at the $y$ early stages of $\mathrm{AD}$ (e.g. GDS stage 3 ). In addition, there have not been many clinical trials on possible prodromes of dementia. ${ }^{[149]}$ It has been argued that this is the best time to treat patients with agents which can halt or slow the deterioration, but researchers have been somewhat reluctant to go deeper into this matter. It is possible that the fact that mild cognitive disorder has until now not been regarded as a nosological or disease entity is the reason for this reluctance. ${ }^{[16]}$ The development of strict criteria for the prodromal or 'predementia' phase of $\mathrm{AD}$ and of methods for its clinical diagnosis would be an important step in the right direction. The treatment of $\mathrm{AD}$ in its predementia phase would then be possible because AD is a nosological entity.

Table II summarises the various aims which are explicitly and implicitly present in drug treatment crildies. Many have hoped to find a treatment for $\therefore$ cause of AD. This is something other than the symptomatic or palliative treatments which are currently the norm. Of course, a cure for the disease should be actively sought, but treatment of one or more symptoms remains of major importance. Finally, as mentioned above, the majority of studies have focused on cognitive symptoms, but the aims of treatment are different depending on whether the clinical psychopharmacological researcher sets out to reverse the course of the disease, or to postpone or slow further decline. The prevention of dementia by treatment in a very early stage is a specific example of postponing or slow-
Table II. Future intervention strategies

Causal pharmacological treatment ('cure')
Pharmacological treatment for one or more symptoms (cure, or
postponing or slowing the process)
Prevention of dementia by pharmacological treatment in a
predementing stage (e.g. age-associated memory impairment
or related condition)
Prevention of age-related cognitive disorders by means of
nutrients, vitamins, dietary supplements and/or herbal extracts
Improved pharmacological treatment, during adulthood, of
depression, anxiety, insomnia, anaesthesia, neurotoxic
exposure, alcohol abuse, neurotrauma with drugs that do not
produce or aggravate cognitive disorders
Psychological treatment of the dementing patient, e.g.
function-oriented guidance
Psychological treatment of primary care-giver
Home training of primary care-givers

ing decline. However, much research is still needed to improve the methodology of the early identification of AD.

Relevant future development may involve drugs which act upon particular brain mechanisms which underlie age-related deficits, for example, drugs acting upon the aggregation of amyloid, on the cleavage of $\beta / A 4$-amyloid protein, and on the Apo $\mathrm{E} 4$ chaperones.

\subsection{Towards the Prevention and Treatment of Cognitive Disorders}

The prescription of psychoactive drugs seems to become more and more dependent on cost-benefit rationales. If it can be proven that chronic use of certain psychoactive substances accelerates cognitive aging, then clinicians should be more cautious in prescribing these drugs even when patients are still young adults.

It must be kept in mind, however, that there are many good reasons to prescribe psychoactive drugs, such as for persistent sleep disorders, anxiety, depressed mood, etc. As these conditions themselves may be accompanied by cognitive disorders, ${ }^{[150,151]}$ treatment with cognition enhancers, as opposed to classical treatments with hypnotics, anxiolytics and antidepressants, may be justified. Nevertheless, it has been argued that in many cases alternatives do exist, for example, antidepressants without 
anticholinergic adverse effects (such as selective serotonin reuptake inhibitors or reversible inhibitors of monoamine oxidase type-A). ${ }^{[152]}$ Another example is the serotonin $5 \mathrm{HT}_{1 \mathrm{~A}}$ agonist anxiolytics which act without impairing memory, and $5 \mathrm{HT}_{3}$ antagonist anxiolytics that may even improve cognition. ${ }^{[153]}$

Although the adverse effect profile of anti-AD drugs should be benign, in the case of treatment of cognitive disorders which are not as severe as $A D$, it seems reasonable to demand a total absence of adverse effects. This is another expression of the 'cost-benefit' attitude towards treating cognitive disorders that are not primarily associated with accepted pathology. Such cognition enhancers could also be used as co-medication to prevent the 'sedating' or 'cognition impairing' effects of psychoactive drugs. Examples from other disciplines illustrate this point.

In the area of allergy treatment, in the last decade there has been a major shift towards the prescription of antihistamines that lack anticholinergic adverse effects, antihistamines that do not readily penetrate the blood-brain barrier, and even antihistamines combined with CNS stimulants. ${ }^{[154,155]}$ Major reasons for the development of these 'new' antihistamines were not so much to increase their anti-allergic efficacy, but to increase their specificity so as to prevent patients with allergies from experiencing drug-induced cognitive impairment on a daily basis and hence to maintain an optimal quality of life.

In general, there is neither a wealth of research nor of clinical experience with drugs to combat the cognitive impairment induced by BLE. However, there are many interesting theoretical possibilities such as a combination of benzodiazepine anxiolytics, anticholinergic antidepressants, anaesthetic agents, alcohol (ethanol) and neurotoxic exposure with nootropic drugs or cognition enhancers. The latter category of drugs reverses or attenuates syndromes of cognitive impairment induced by cholinergic dysfunction. ${ }^{[156-159]}$

Several piracetam analogues, i.e. tenilsetam, aniracetam, and oxiracetam, ${ }^{[160,161]}$ have been shown to attenuate anticholinergic and hypoxic effects on cognition. The piracetam-like nootropic compounds have few adverse effects and hence could be candidate substances for co-prescription with psychoactive drugs known to impair cognition.

Finally, it is worth mentioning that many patients who are treated with antidepressant, anxiolytic or hypnotic drugs are probably attenuating their drug-induced cognitive impairment by habitually consuming products containing nicotine and caffeine, i.e. smoking tobacco and drinking coffee. Nicotine, a nicotinic cholinergic agonist, has been repeatedly demonstrated to possess the property of antagonising the effects of anticholinergic ag on cognition. ${ }^{[162-164]}$ Caffeine attenuates the memory impairment induced by cholinergic blockade, ${ }^{[162]}$ benzodiazepine-induced cognitive impairment, ${ }^{[165]}$ and even the cognitive-impairing effects of alcohol. ${ }^{[166]}$

However, chronic use of caffeine has been shown to be associated with an improvement of cognitive performance. ${ }^{[167]}$ Also the use of nicotine, despite its known association with an increased risk of cancer, has been shown to be associated with improved cognitive performance ${ }^{[168]}$ and even with a lower incidence of AD. ${ }^{[169]}$

Dietary supplements, vitamins, trace elements and flavenoids may prevent cognitive disorders, particularly those associated with aging, fatigue or daily intake of alcohol. Studies have demonstrated an association between the use of thiamine (vitamin B1), ${ }^{[170]}$ pyridoxine (vitamin B6) ${ }^{[171]}$ or cyan cobalamin (vitamin B12), ${ }^{[172]}$ and cognition. Ho 4 ever, one has to assume that a depletion, whether experimental, clinical or subclinical, of those vitamins must exist to explain these effects.

Altered levels of trace elements may play a role in the development of cognitive disorders, and memory complaints may be the clinical expression of a disturbed balance in micronutritional elements, such as trace elements or minerals. We have found that, among other elements, decreased levels of zinc are associated with increasing age. ${ }^{[173]}$ Furthermore, zinc blood level and psychological performance were positively correlated, independent 
of age. ${ }^{[174]}$ However, when we searched for the reverse association, i.e. lowered levels of zinc or other trace elements as putative biological markers in persons with AAMI as compared with agematched controls, we could not find one. ${ }^{[175]}$

\section{Conclusion}

Research into the borderline states between normal aging and dementia is underdeveloped compared to the vast amount of knowledge which has been gained on normal cognitive aging and on dementing conditions (especially AD). A major

blem may be the fact that the nosological status and clinical characteristics of these intermediary stages have only recently been elucidated. This has prevented clinicians from developing diagnostic and treatment programmes, and drug companies have not been stimulated to put much effort in developing drugs for a nonexistant disease.

Until now, many consider the development of drugs for a normal physiological process (i.e. the aging process) not rational. However, the view that 'normal' aging needs no treatment should in our view be replaced by more subtle options, e.g. a distinction between primary and secondary aging.

The borderline between primary aging, which is exclusively determined by chronological age, and clear-cut dementia is very subtle: many people experience secondary aging, the symptoms of which are only normal in a statistical sense but not in a physiological sense. This is a good reason to de-

op specific drugs for the nondemented populatron experiencing age-related cognitive decline. The recent incorporation of the classes of 'cognitive disorder' and 'age-related cognitive decline' in DSM-IV may herald a positive change of attitude in this respect. ${ }^{[108,176]}$ Otherwise it might be worthwile to target subgroups of cognitive disorders in terms of recognised factors that compromise successful aging. Clinical trials with nootropic drugs to prevent cognitive impairment after BLE such as closed head injury that are currently being carried out are an example. Nootropic drugs or cognition enhancers as co-medication against the cognitive impairment caused by psychoactive drugs used to treat depression, anxiety, insomnia or allergy could be a positive contribution in the struggle to achieve successful aging.

\section{References}

1. Jolles J. Cognitive, emotional and behavioral dysfunctions in aging and dementia. In: Swaab DF, Fliers E, Mirmirian M, et al., editors. Progress in brain research. Amsterdam: Elsevier Science Publishers, 1986; 70: 15-39

2. Birren JE, Warner Schaie K, editors. Handbook of the psychology of aging. 3rd ed. New York: Van Nostrand Reinhold Company, 1990

3. Botwinick J. Aging and behavior. 3rd ed. New York: Springer 1984

4. Charness N, editor. Aging and human performance. Chichester: John Wiley \& Sons, 1985

5. Salthouse TA. Speed of behavior and its implications for cognition. In: Birren JE, Schaie KW, editors. Handbook of the psychology of aging. New York: Van Nostrand Reinhold, 1985: 400-26

6. Masur DM, Sliwinski M, Lipton RB, et al. Neuropsychological prediction of dementia and the absence of dementia in healthy elderly persons. Neurology 1994; 44: 1427-32

7. Ban TA. Psychopharmacology and successful cerebral aging. Prog Neuropsych Biol Psychiatry 1994; 19: 1-9

8. Michel B, Sambuc R, Scotto JC. French recommendations for clinical drug trials in cognitive disorders of the elderly. Int $\mathrm{J}$ Geriatr Psychiatry 1994; 9 (10): 823-28

9. O'Brien JT, Levy R. Age associated memory impairment. BMJ 1992; 304: 5-6

10. Verhey FRJ, Jolles J, Ponds RWHM, et al. Diagnosing dementia: comparison between a monodisciplinary and a multidisciplinary approach. J Neuropsychiatry Clin Neurosci 1993; 5 (1): 78-85

11. Huppert FA. Age-related changes in memory: learning and remembering new information. In: Boller F, Grafman J, editors. Handbook of neuropsychology. Amsterdam: Elsevier Science Publishers, 1991: 123-47

12. LaRue A. Aging and neuropsychological assessment. New York: Plenum Press, 1992

13. Huppert FA, Tym E. Clinical and neuropsychological assessment of dementia. Br Med Bull 1986; 42: 11-8

14. Morris JC, Heyman A, Mohs RC, et al. The Consortium to Establish a Registry for Alzheimer's Disease (CERAD). Neurology 1989; 39: 1159-65

15. Storandt M, Botwinick J, Danziger WL, et al. Psychometric differentiation of mild dementia of the Alzheimer type. Arch Neurol 1984; 41: 497-9

16. Amaducci L, Angst J, Bech P, et al. Consensus conference on the methodology of clinical trials of 'nootropics'; 1989 Jun 28-30: Munich. Report of the consensus committee. Pharmacopsychiatry, 1990; $23(4): 171-5$

17. Gray JA, Enz A, Spiegel R. Muscarinic agonists for senile dementia: past experience and future trends. Trends Pharmacol Sci $1989 ; 10: 85-8$

18. Thal LJ. Clinical trials in Alzheimer's disease. In: Terry RD, Katzman R, Bick KL, editors. Alzheimer's disease. New York: Raven Press, 1994: 431-44

19. Whalley LJ. Drug treatments of dementia. Br J Psychiatry 1989; 155: 595-611

20. Riedel WJ, Jolles J. Cognition enhancers in age-related cognitive decline. Drugs Aging. In press 
21. Birren JE, Wamer Schaie K, editors. Handbook of the psychology of aging. 2nd ed. New York: Van Nostrand Reinhold Company, 1985

22. Reese HW, Rodeheaver D. Problem solving and decision making. In: Birren JE, Schaie KW, editors. Handbook of the psychology of aging. 2nd ed. New York: Van Nostrand Reinhold, 1985: 474-99

23. Plude DJ, Hoyer WJ. Attention and performance: identifying and localizing age deficits. In: Charness $\mathbf{N}$, editor. Aging and human performance. Chichester: Wiley, 1985: 47-99

24. Woodruff DS. Arousal, sleep, and aging. In: Birren JE, Schaie $\mathrm{KW}$, editors. Handbook of the psychology of aging, New York: Van Nostrand Reinhold, 1985: 261-95

25. Salthouse TA. Resource-reduction interpretations of cognitive aging. Dev Rev 1988; 8 (3): 238-72

26. Houx PJ, Vreeling FW, Jolles J. Rigorous health screening reduces age effect on memory scanning task. Brain Cogn 1991; 15 (2): 246-60

27. Rabbitt PMA. Applied cognitive gerontology: some problems, methodologies and data. Appl Cogn Psychol 1990; 4: 225-46

28. Haug H. Are neurons of the human cerebral cortex really lost during aging? In: Traber J. Gispen WH, editors. Senile dementia of the Alzheimer type. Berlin: Springer Verlag, 1985: 150-63

29. Riegel KF, Riegel RM. A study of the drop-out rates in longitudinal research on aging and the prediction of death. J Pers Soc Psychol 1967; 4: 342-8

30. Riegel KF, Riegel RM. Development, drop, and death. Dev Psychol 1972; 6: 309-16

31. Houx PJ, Vreeling FW, Jolles J. Stroop interference: aging effects assessed with the Stroop Color-Word Test. Exp Aging Res 1993; 19: 209-24

32. Jolles J, Houx PJ, Vreeling FW, et al. Cognitive aging, biological life events and primitive reflexes. Neurosci Res Commun 1994; 13 Suppl. 1: S47-S50

33. Rabbitt PMA, Goward LM. Effects of age and raw IQ test scores on mean correct and mean error reaction times in serial choice tasks: a reply to Smith \& Brewer. Br J Psychol 1986; 77 (1): $69-73$

34. Geffen G, Moar KJ, O'Hanlon AP, et al. Performance measures of 16- to 86-year-old males and females on the auditory verbal learning test. Clin Neuropsychologist 1990; 4 (1): 45-63

35. Verillo RT, Verillo V. Sensory and perceptual performance. In Charness N, editor. Aging and human performance. Chichester: Wiley, 1985: 1-46

36. Stones MJ, Kozma A. Physical performance. In: Charness N, editor. Aging and human performance, Chichester: Wiley, 1985: 261-91

37. Houx PJ, Jolles J. Vulnerability factors for age-related cognitive decline. In: Isaacson RL, Jensen KF, editors. The vulnerable brain and environmental risks. New York: Plenum Press, 1994: $25-41$

38. Houx PJ, Vreeling FW, Jolles J. Age-associated cognitive decline is related to biological life events. In: Iqbal $\mathrm{K}$, McLachlan DRC, Winblad B, et al., editors. Alzheimer's disease: basic mechanisms, diagnosis and therapeutic strategies. Chichester: John Wiley \& Sons Ltd, 1991: 353-9

39. Houx PJ, Jolles J. Age-related decline of psychomotor speed: effects of age, brain health, sex and education. Percept Mot Skills 1993; 76: 195-211

40. Vreeling FW, Jolles J, Verhey FRJ, et al. Primitive reflexes in Alzheimer's disease and vascular dementia. J Geriatr Psychiatry Neurol 1995; 8 (2): 111-7
41. Fozard JL, Metter EJ, Brant LJ. Next steps in describing aging and disease in longitudinal studies. J Gerontol 1990; 43 (4): 116-27

42. Colsher PL, Wallace RB. Epidemiologic considerations in studies of cognitive function in the elderly: methodology and nondementing acquired dysfunction. Epidemiol Rev 1991; 13 (1): 1-27

43. Haxby JV, Grady CL, Duara R, et al. Relations among age, visual memory, and resting cerebral metabolism in $\mathbf{4 0}$ healthy men. Brain Cogn 1986; 5: 412-27

44. Christensen KJ, Moye J, Armson RR, et al. Health screening and random recruitment for cognitive aging research. Psychol Aging 1992; 7: 204-8

45. Elias MF, Robbins MA, Schultz NR, et al. Is blood pressure an important variable in research on aging and neuropsychological test performance? J Gerontol 1990; 45 (4): 128-35

46. Hartman DE. Neuropsychological toxicology: identification and assessment of human neurotoxic syndromes. New York Pergamom Press, 1988

47. Hijman R, Jolles J, Verhoeven WMA, et al. Desglycinar. (Arg(8))-vasopressin in five trials with memory-disturbed patients. Hum Psychopharmacol 1992; 7 (1): 7-23

48. Rowe JW, Kahn RL. Human aging: usual and successful. Science $1987 ; 237: 143-9$

49. Stones MJ, Kozma A, Hannah TE. The measurement of individual differences in aging: the distinction between usual and successful aging. In: Howe ML, Stones MJ, Brainerd CJ, editors. Cognitive and behavioral performance factors in atypical aging. New York: Springer Verlag, 1990: 181-218

50. Kay D, Bergmann K, Foster EM, et al. Mental illness and hospital usage in the elderly: a random sample followed up. Compr Psychiatry 1970; 11 (1):26-35

51. Henderson AS, Huppert FA. The problem of mild dementia. Psychol Med 1984; 14: 5-11

52. Henderson AS. The epidemiology of Alzheimer's disease. $\mathrm{Br}$ Med Bull 1986; 42: 3-10

53. Freemon F. Evaluation of patients with progressive intellectual deterioration. Arch Neurol 1976; 33: 658-9

54. Hachinski V. Preventable dementia: a call for action against the vascular dementias. Lancet 1992; 340: 645-8

55. Marsden $C$, Harrison M. Outcome of investigation of patients with presenile dementia. BMJ 1972; 2 (808): 249-52

56. Smith J, Kiloh L. The investigation of dementia: results in 200 consecutive admissions. Lancet 1981; ii: 824-7

57. Clarfield AM. The reversible dementias: do they reverse? Intern Med 1988; 109: 476-86

58. Larson EB, Reifler BV, Sumi SM, et al. Diagnostic evaluation of 200 elderly outpatients with suspected dementia. J Gerontol $1985 ; 40: 536-43$

59. Jolles J, Verhey FRJ. On the rationale behind treatment studies in cognitive aging and dementia. Paper presented at the $\mathrm{Alz}$ heimer's Disease: back to the future. Amsterdam, 9 Oct 1992 Proceedings of the symposium on Alzheimer's disease: recent advances in diagnosis and treatment. Amsterdam: Free University, 1993: 75-84

60. Commissaris CJAM, Verhey FRJ, Ponds RWHM, et al. Public education about normal forgetfulness and dementia: importance and effects. Patient Educ Couns 1994; 24: 109-15

61. Commissaris CJAM, Jolles J, Verhey FRJ, et al. Forgetfulness or dementia? Who is worried and why. Eur J Public Health 1995. In press

62. Commissaris CJAM, Ponds RWHM, Verhey FRJ, et al. Public education about normal forgetfulness and dementia: effec- 
tiveness of a systematically developed information brochure. Educ Gerontol 1995; 21: 763-77

63. Philpot MP, Levy R. Memory clinic for the early diagnosis of dementia. Int J Geriatr Psychiatry 1987; 2: 195-200

64. Aevarsson O, Skoog I. Prodromal symptoms of dementia. Neurobiol Aging 1992; 13 Suppl.: 5L

65. Persson G, Berg S, Nilsson L, et al. Subclinical dementia. Relation to cognition, personality and psychopathology: a nineyear prospective study. Int I Geriatr Psychiatry 1991; 6: 239-47

66. Rubin EH, Kinscherf DA. Psychopathology of very mild dementia of the Alzheimer type. Am J Psychiatry 1989; 146: 1017-21

67. Bozolla FG, Gorelick PB, Freels S. Personality changes in Alzheimer's disease. Arch Neurol 1992; 49: 297-300

68. Chatterjee A, Strauss ME, Smyth KA, et al. Personality changes in Alzheimer's disease. Arch Neurol 1992; 49: 486-91

69. Petry S, Cummings JL, Hill MA, et al. Personality alterations in dementia of the Alzheimer type. Arch Neurol 1988; 45: $1187-90$

iv. Rubin EH, Morris JC, Berg L. The progression of personality changes in patients with mild senile dementia of the Alzheimer type. J Am Geriatr Soc 1987; 35: 721-5

71. Bolla KI, Lindgren KN, Bonaccorsy C, et al. Memory complaints in older adults. Fact or fiction? Arch Neurol 1991; 48 (1): $61-4$

72. Christensen, $H$. The validity of memory complaints by elderly people. Int J Geriatr Psychiatry 1991; 6: 307-12

73. McGlone J, Gupta S, Humphrey D, et al. Screening for early dementia using memory complaints from patients and relatives. Arch Neurol 1990; 47: 1189-93

74. O'Brien JT, Beats B, Hill K, et al. Do subjective memory complaints precede dementia? A three year follow-up study of patients with supposed 'benign senescent forgetfulness'. Int J Geriatr Psychiatry 1992; 7: 481-6

75. O'Connor DW, Pollitt PA, Roth M, et al. Memory complaints and impairment in normal, depressed and demented elderly persons identified in a community survey. Arch Gen Psychiatry $1990 ; 47: 224-7$

76. Plotkin DA, Mintz JM, Jarvik LF. Subjective memory complaints in geriatric depression. Am J Psychiatry 1985; 142: 1103-5

77. Frederiks JAM. The neurology of aging and dementia. In: Bruyn D, editor. Handbook of clinical neurology. Amsterdam: Elsevier Science Publishers, 1985; 46: 199-219

78. Galasko D, Kwo-on-Yuen PF, Klauber MR, et al. Neurological 1 findings in Alzheimer's disease and normal aging. Arch Neurol 1990; 47: 625-7

79. Storandt M, Hill RD. Very mild senile dementia of the Alzheimer type: 2. Psychometric test performance. Arch Neurol 1989; 46: 383-6

80. Rubin EH, Morris JC, Grant EA, et al. Very mild senile dementia of the Alzheimer type: 1. Clinical assessment. Arch Neurol 1989; 46: 379-82

81. Jobst KA, Smith AD, Szatmari M, et al. Detection in life of confirmed Alzheimer's disease using a simple measurement of medial temporal lobe atrophy by computed tomography. Lancet $1992 ; 340: 1179-83$

82. Weinstein H. SPECT in Alzheimer's disease. Amsterdam: University Press, 1992

83. Scheltens P, Leys D, Barkhof F. Hippocampal atrophy on magnetic resonance imaging in Alzheimer's disease and normal aging. Neurology 1991; 41 Suppl. 1: 341-2

84. Soininen HS, Partanen K, Pitkanen A, et al. Volumetric MRI analysis of the amygdala and the hippocampus in subjects with age-associated memory impairment: correlation to visual and verbal memory. Neurology 1994; 44 (9): 1660-8

85. Robins E, Guze SB. Establishment of diagnostic validity in psychiatric illness: its application to schizophrenia. Am J Psychiatry 1970; 126: 983-7

86. Verhey FRJ, Rozendaal N, Ponds RWHM, et al. Dementia, depression and awareness. Int J Geriatr Psychiatry 1993; 8: 851-6

87. American Psychiatric Association. Diagnostic and statistical manual of mental disorders. 3rd rev. ed. Washington DC: American Psychiatric Association, 1987

88. Chui HC, Teng EL, Henderson VW, et al. Clinical subtypes of dementia of the Alzheimer type. Neurology 1985; 35: 1544-50

89. McKhann G, Drachmann D, Folstein M, et al. Clinical diagnosis of Alzheimer's disease: report of the NINCDS-ADRDA workgroup under the auspices of the department of Health and Human Services task force on Alzheimer's disease. Neurology 1984 ; 34: 939-44

90. Román GC, Tatemichi TK, Erkinjuntii T, et al. Vascular dementia: diagnostic criterion for research studies. Report of the NINAIREN international workshop. Neurology 1993; 43: 250-60

91. American Psychiatric Association. Diagnostic and statistical manual of mental disorders. 4th ed. Washington D.C.: American Psychiatric Association, 1994

92. Roth M, Tym E, Mountjoy CQ, et al. CAMDEX: a standardised instrument for the diagnosis of mental disorder in the elderly with special reference to the early detection of dementia. $\mathrm{Br}$ J Psychiatry 1986; 149: 698-709

93. Hachinski V, Illif L, Zilkha E, et al. Cerebral blood flow in dementia. Arch Neurol 1975; 32: 632-7

94. Rosen WG, Mohs RC. Evolution of cognitive decline in dementia. In: Corkin S, editor. Alzheimer's disease: a report of progress. New York: Raven Press, 1982: 183-8

95. Chui HC, Victoroff JI, Margolin D, et al. Criteria for the diagnosis of ischemic vascular dementia proposed by the State of California Alzheimer's Disease Diagnostic and Treatment Centers. Neurology 1992; 42: 473-80

96. Verhey FRJ, Lodder J, Rozendaal N, et al. Criteria for the clinical diagnosis of vascular dementia: a comparison between seven current sets. Neuroepidemiology. In press

97. Kral VA. Neuro-psychiatric observations in an old people's home. J Gerontol 1958; 13: 169-76

98. Reisberg B, Ferris SH, De Leon MJ, et al. The Global Deterioration Scale for assessment of primary degenerative dementia. Am J Psychiatry 1982; 139 (9): 1136-9

99. Hughes CP, Berg L, Danziger WL, et al. A new rating scale for the staging of dementia. Br J Psychiatry 1982; 140: 566-72

100. Crook T, Bartus RT, Ferris SH, et al. Age-associated memory impairment: proposed diagnostic criteria and measures of clinical change. Report of a National Institute of Mental Health work group. Dev Neuropsychol 1986; 2 (4): 261-76

101. Blackford RC, LaRue A. Criteria for diagnosing age-associated memory impairment: proposed improvements from the field. Dev Neuropsychol 1989; 5 (4): 295-306

102. Caine ED. Should aging-associated cognitive decline be included in DSM-IV? J Neuropsychiatry Clin Neurosci 1993; 5 (1): $1-5$

103. Spitzer R, First MB, Williams JBW, et al. Now is the time to retire the term 'organic mental disorders'. Am J Psychiatry 1992; 149: $240-4$

104. Dawe B, Procter A, Philpot M. Concepts of memory impairment in the elderly and their relationship to dementia - a review. Int J Geriatr Psychiatry 1992; 7: 473-9 
105. Kral VA. Senescent forgetfulness: benign and malignant. Can Med Assoc J 1962; 86: 257-60

106. Ferris SH, Flicker C, Reisberg B, et al. Age-associated memory impairment, benign forgetfulness and dementia. In: Bergener M, Reisberg B, editors. Diagnosis and treatment of senile dementia. Berlin: Springer Verlag, 1989: 72-82

107. McEntee WJ, Crook TH. Age-associated memory impairment: a role for catecholamines. Neurology 1990; 40: 526-30

108. Derouesné C, Kalafat M, Guez D, et al. The age-associated memory impairment construct revisited. Int J Geriatr Psychiatry 1994; 9: 577-87

109. Popkin MK, Tucker G, Caine E, et al. The fate of organic mental disorders in DSM-VI: a progress report. Psychosomatics 1989; 30: 438-41

110. Spitzer R, Williams JBW, First M. A proposal for DSM-IV solving the 'organic-nonorganic' problem. J Neuropsychiatry Clin Neurosci 1989; 1 (2): 126-27

111. Forette F, Henry J, Orgogozo J. Reliability of clinical criterion for the diagnosis of dementia. Arch Neurol 1989; 46: 646-8

112. Huff FJ, Becker JT, Belle SH, et al. Cognitive deficits and clinical diagnosis of Alzheimer's disease. Neurology 1987; 37 : 1119-24

113. Nielsen H, Lolk A, Pedersen I, et al. The accuracy of early diagnosis and predictors of death in Alzheimer's disease and vascular dementia - a follow-up study. Acta Psychiatr Scand 1991; 84: 277-82

114. Burke WJ, Miller JP, Rubin EH, et al. The reliability of the Washington University Clinical Dementia Rating. Arch Neurol $1988 ; 45: 31-2$

115. Berg L, Miller JP, Baty J, et al. Mild senile dementia of the Alzheimer type. 3. Longitudinal and cross-sectional assessment. Ann Neurol 1990; 28: 648-52

116. Roth M, Huppert FA, Tym E, et al. CAMDEX: the Cambridge examination for mental disorders of the elderly. Cambridge: University Press, 1988

117. O'Connor D, Pollit PA, Hyde JB, et al. Clinical issues relating to the diagnosis of mild dementia in a British community survey. Arch Neurol 1991; 48: 530-4

118. O'Connor DW, Pollit PA, Hyde JB, et al. A follow-up study of dementia diagnosed in the community using the Cambridge Mental Disorders of the elderly examination. Acta Psychiatr Scand 1990; 81: 78-82

119. Fratiglioni FY, Grut M, Viitanen GM, et al. Clinical staging of dementia in a population survey: comparison of DSM-III-R and the Washington University Clinical Dementia Rating scale. Acta Psychiatr Scand 1992; 86: 49-54

120. Mowry BJ, Burvill PW. A study of mild dementia in the community using a wide range of diagnostic criterion. Br J Psychiatry $1988 ; 153: 328-34$

121. Hultsch DF, Hertzog C, Dixon RA, et al. Memory self-knowledge and self-efficacy in the aged. In: Lowe ML, Brainerd CJ, ed itors. Cognitive development in adulthood: progress in cognitive developmental research. New York: Springer Verlag, 1988: 65-92

122. Shimamura AP, Squire LR. Memory and metamemory: a study of the feeling-of-knowing phenomenon in amnestic patients. J Exp Psychol 1986; 12: 452-60

123. Sunderland A, Watts K, Baddeley AD, et al. Subjective memory assessment and test performance in elderly adults. J Gerontol 1986; 41: 376-84

124. Reding M, Haycox J, Blass J. Depression in patients referred to a dementia clinic: a three year prospective study. Arch Neurol 1985; 42: 894-6
125. Welsh K, Butters N, Hughes J, et al. Detection of abnormal memory decline in mild cases of Alzheimer's disease using CERAD neuropsychological measures. Arch Neurol 1991; 48: 278-81

126. Berrios GE. Non-cognitive symptoms and the diagnosis of dementia: history and clinical aspects. Br J Psychiatry 1989; 154 Suppl. 4: 11-6

127. Folstein MF, Bijlsma PW. Noncognitive symptoms of Alzheimer's disease. In: Terry R, Katzman R, Bick K, editors. Alzheimer disease. New York: Raven Press, 1994: 27-40

128. Rabins PV. Noncognitive symptoms in Alzheimer's disease: definitions, treatments and possible etiologies. In: Terry $R$, Katzman R, Bick K, editors. Alzheimer disease. New York: Raven Press, 1994: 419-30

129. Brayne $C$, Calloway $P$. Normal ageing, impaired cognitive function, and senile dementia of the Alzheimer's type: a continuum? Lancet 1988; i (8597): 1265-7

130. Kiloh LG. Pseudodementia. Acta Psychiatr Scand 1961; 37 336-51

131. Kral VA, Emery $O$. Long term follow-up of depressive ps , dementia. Can J Psychiatry 1989; 34: 445-7

132. Roberts JKA. Differential diagnosis in neuropsychiatry. Chichester: Wiley \& Sons, 1984

133. LaRue A, Watson J, Plotkin DA. First symptoms of dementia: a study of relatives' reports. Int J Geriatr Psychiatry 1993; 8 : 239-45

134. Katzman R, Aronson M, Fuld P, et al. Development of dementing illnesses in an 80-year-old volunteer cohort. Ann Neurol $1989 ; 25: 317-24$

135. Crystal H, Dickson D, Fuld P, et al. Clinico-pathological studies in dementia: nondemented subjects with pathologically confirmed Alzheimer's disease. Neurology 1988; 38: 1682-7

136. Amaducci L, Fratiglioni L. Epidemiology of AD: impact on the treatment. In: Giacobini E, Becker RE, editors. Alzheimer's disease: therapeutic strategies. Basel: Birkhäuser Verlag, 1994: 8-16

137. Katzman R, Kawas CH. The epidemiology of dementia and Alzhmeimer's disease. In: Terry R, Katzman R, Bick K, editors. Alzheimer disease. New York: Raven Press, 1994: 105-22

138. Fenn H, Luby V, Yesavage JA. Subtypes in Alzheimer's disease and the impact of excess disability: recent findings. Int $J$ Geriatr Psychiatry 1993; 8: 67-73

139. Ritchie K, Touchon J. Heterogeneity in senile dementia of the Alzheimer type: individual differences, progressive deterioration or clinical subtypes? J Clin Epidemiol 1992; 45: 13Q48

140. Corder E, Sauders A, Strittmaier W, et al. Gene dose of apc protein $\mathrm{E}$ Type 4 allele and the risk of Alzheimer's disease in late onset families. Science 1993; 261: 921-3

141. Scinto LFM, Daffner KM, Dressler D, et al. A potential noninvasive neurobiological test for Alzheimer's disease. Science 1994; 266: 1051-4

142. Food and Drug Administration. Tacrine as a treatment for Alzheimer's Dementia. An interim report from the FDA. N Engl J Med 1991; 324: 349-52

143. Giacobini E, Becker R. Development of drugs for Alzheime therapy: a decade of progress. In: Giacobini E, Becker RE editors. Alzheimer's disease: therapeutic strategies. Basel: Birkhäuser Verlag, 1994: 1-7

144. Wolkowitz OM. Tinklenberg JR, Weingartner HA. Psychopharmacological perspective of cognitive functions. Neuropsychobiology 1985; 14: 88-96

145. Corkin S, Growdon JH, Sullivan EV, et al. Assessing treatment effects: a neuropsychological battery. In: Poon LW, editor Handbook for clinical memory assessment of older adults. 

Washington: American Psychological Association, 1986:
$156-7$

146. Tyrell P, Hardy J, Rosor M. Tetrahydroaminoacridin heimer's disease. Lancet 1987 , i (8530): 444 in Alzheimer's

147. Jansen KLR. Is treating memory impairment 1988; 11: 210 disease an objective? Trends Neu WA. Tetrahydroamine-

148. Weinstein HC, Teunisse S, Van Gool WA. Tetreimer's disease: acridine and lecithine in treatment of Alzheimers behavioral diseffect on cognition, functioning in daily the carers. $J$ Neurol turbances and b

1991; 238: 34-8

149. Crook T. Pharmacotherapy of cognitive deficits in Alzheiments disease and age associated memc pharmacol Bull 1988; 24: 31-8

150. Brand N, Jolles J. Information processing in anxiety. Psychol Med 1987; 17 (1): 145-53

151. Nilsson LG, Backman L, Karlsson T. Prim deprived subjects: a in elderly, alcohol intoxicated and sleep deficits. Psychol Med case of functionally

1989; 19 (2): 423-33

152. Riedel WJ, Van Praag HM. Avoiding and managing anticholin(4) ergic effects of antidepressants. Ciazepines and 5-HT 1 a agonists

153. Lister RG. The effects of benzodiazepines and Cooper SJ, editors. on learning and memory. In: Rodgers RJ, Coopediazepines. 5-HT $\mathrm{HA}_{1 \mathrm{~A}}$ agonists, $5-\mathrm{HT}_{3}$ antagon Chichester: Wiley, 1991: 267-80

154. Gaillard AWK, Gruisen A, De Jong R. The Influence of antihistamines on human performance. Eur J Clin Pharmacol 1988; 35 (3): 249-54

155. Ramaekers JG, O'Hanlon JF. Acrivastine, terfenadine and diphenhydramine effects on driving performance as a function of dose and time after dosing. Eur J Clin Pharmacol 1994; 47 (3): $261-6$

156. Jones RW, Wesnes KA, Kirby J. Effects of NMDA modulation in scopolamine dementia. Ann NY Acad Sci 1991; 640: 241-4

57. Molchan SE, Mellow AM, Lawlor BA, et al. TRH attenuates scopolamine-induced memory impairment in humans. Psychopharmacol 1990; $100(1): 84-9$

158. Preston GC, Ward C, Lines CR, et al. Scopolamine and benzodiazepine models of dementia: cross-reversals by Ro 15-1788 and physostigmine. Psychopharmacology 1989; 98 (4): 487-94

159. Wesnes K, Jones RW, Kirby J. The effects of D-cycloserine, a glycine agonist, in a human model of the cognitive deficits associated with ageing and dementia. Br J Clin Pharmacol 1991; 31: 577-8

Preda L, Alberoni M, Bressi S, et al. Effects of acute doses of oxiracetam in the scopolamine model of human amnesia. Psychopharmacology 1993; 110 (4): $421-6$

161. Wesnes KA, Anand R, Simpson PM, et al. The use of a scopolamine model to study the potential nootropic effects of aniracetam and piracetam in healthy volunteers. J Psychopharmacol 1990; 4 (4): 219-32
62. Riedel WJ, Hogervorst E, Leboux RLAM, et al. Caffeine attenuates scopolamine-induced memory impairment in humans. Psychopharmacology. In press

Psych Faton-Williams P. Distinguishing between attentional

163. Rusted J, Eaton-Williams P. Distinguishing and amnestic effects in information processing. the seprol and combined effects of scopolamine and 104 (3): 363-6 free recall. Psychopharmacology 1991 .

164. Wesnes K, Revell A. The separate and information processing. polamine and nicotine on hus (1): 5-11 Psychopharmacology 1984; 84 (1): 5-11

165. Rush CR, Higgins ST, Hughes JR, et al. Acut in combination, in fects of triazolam and caffeine, alone and in comb: 211-22 humans. Exp Clin Psychopharmacol et al. Antagonistic effects

166. Hasenfratz M, Bunge A, Dal Pra G, et al. Anance parameters. of caffeine and alcohol on mental perfor : 463-5 Pharmacol Biochem Behav 1993; 46 (2): 463-5

167. Jarvis M. Does caffeine intake enhance absolute levi 110:45-52 nitive performance? Psychophar nicotine and human perfor-

168. Wesnes K, Parrott A. Smoking, nicotine and human London: Acamance. Handbook of hum demic Press, 1992: 127-67

169. Van Duijn M, Hofman A. Relation between nicotine intake and Dimer's disease. BMJ 1991; 302: 1491-4

70. Meador KJ, Nichols ME, Franke $P$, et al. Evidence for a central cholinergic effect of high-dose thiamine. Ann Neurol 1993; 34 (5): 724-6

71. Deijen JB, Van der Beek EJ, Orlebeke JF, et al. Vitamin B-6 supplementation in elderly men: effects on mood, memory, performance and mental effort. Psychopharmacology 1992; 109 (4): 489-96

72. Bohnen N Jolles I Degenaar CP. Lower blood levels of vitamin $B 12$ are related to decreased performance of healthy subjects in the Stroop Color Word Test. Neurosci Res Commun 1992; 11 (1): 53-6

173. Bohnen N, Jolles J, Degenaar CP. Levels of trace elements in blood in healthy ageing subjects. Z Gerontol 1994; $27: 324-7$

174. Jolles J, Houx PJ, Vreeling FW, et al. Biological risk factors for accelerated cognitive aging and dementia: findings from a multiple cohort study. Neurobiol Aging 1990; 11 (3): 293

75. Riedel WJ, Jolles J. Decreased blood level of zinc: does it explain age-associated-memory-impairment? Neuropsychopharmacology 1993; 9 (2 Suppl.): 57

176. Levy R. Aging-associated cognitive decline: working party of the International Psychogeriatric Association in collaboration with WHO. Int Psychogeriatr 1994; 6: 63-8

Correspondence and reprints: Prof Dr J. Jolles, University of Limburg, Department of Psychiatry and Neuropsychology, Section of Neuropsychology, P.O. Box 616, $6200 \mathrm{MD}$ Maastricht, The Netherlands. 